\title{
Complex relational units in Danish orthography
}

\section{CHRISTIAN BECKER-CHRISTENSEN}

Similar to other orthographies, Danish "retskrivning" includes complex relational units, graphemic units as $\langle\mathrm{sj}>[\mathrm{c}]$ in sjel 'soul', to a lesser extent also phonemic units as [dj] represented by a single grapheme $<\mathrm{j}>$ in $j o b$.

The present paper deals with such complex relations in respect to the delimitation of graphemic units, their function, and their role in orthographic regulation. The investigation relates to the search facility Bogstavlyd (bogstavlyd.ku.dk) and Juul (2010).

Three types of complex graphemic units are distinguished: endocentric and exocentric combinations, e.g. $\langle\mathrm{hv}\rangle[\mathrm{v}]$ and $\langle\mathrm{sj}\rangle[\mathrm{6}]$, and endo-exocentric combinations functioning differently internally and externally in relation to the word as a whole, and the treatment of these combinations as units or sequences in orthographic descriptions with zero correspondences is discussed in the light of minimizing the inventory of graphemic units and providing a basis for general orthographic rules (reference is made to Venezky 1970 and Carney 1994).

Some exocentric units are phonographemically necessary units, others are substitutable with single graphemes or other exocentric units. In some more recent loanwords the foreign spelling is functional, marking a sound structure deviant from the Danish main sound structure. Most complex graphemic units contribute to graphemic redundancy and may cause a problem especially to the graphophonemic decoder in recognizing the right delimitation as well as finding the right correspondence.

According to Juul (2010), complex graphemic units account for a minor part of sound-letter-sound relations in Danish orthography. Some of the more frequent combinations are units such as $<\mathrm{hj}$, hv, ld, $\mathrm{nd}, \mathrm{rd}>$ which are not productive in the vocabulary except from compositional and derivational words. On the other hand, in more recent 
times especially words from English contribute to complex graphemic units which before 1955 were infrequent or unknown to Danish orthography. So far, the regulation of foreign spellings has concerned mainly words from Greek, Latin and French. 